\title{
Underreporting of communicable diseases in the prefecture of Achaia, western Greece, 1999-2004 - missed opportunities for early intervention
}

E Jelastopulu' ${ }^{1}$, G Merekoulias ${ }^{1}$, E C Alexopoulos (ecalexop@upatras.gr) ${ }^{1}$

1. Department of Public Health, School of Medicine, University of Patras, Greece

Citation style for this article:

Citation style for this article: Jelastopulu E, Merekoulias G, Alexopoulos EC. Underreporting of communicable diseases in the prefecture of Achaia, western Greece, 1999-2004-missed opportunities for early intervention. Euro Surveill. 2010;15(21):pii=19579. Available online: http://www.eurosurveillance.org/ViewArticle.

aspx?Articleld $=19579$

This article has been published on 27 May 2010

This study investigates the completeness of the reporting of infectious diseases in the prefecture of Achaia, western Greece in the period of 1999-2004. We collected hospital records relating to infectious diseases retrospectively from three major hospitals in the region and compared the records to corresponding records at the prefectural public health department (PHD). After record-linkage and cross-validation a total of 1,143 notifiable cases were identified in the three hospitals, of which 707 were reported to the PHD of Achaia, resulting in an observed underreporting of infectious diseases of $38 \%$ during the study period. At prefecture level, a further 259 cases were notified by other sources, mainly by the fourth hospital of the region not included in our study, resulting in a total of 966 cases reported to the PHD; $73 \%$ of these were reported from the three hospitals included in our study, $\mathbf{2 7} \%$ were notified by the fourth hospital not included in our study and less then $0,3 \%$ by physicians working in a private practice or health centre. Meningitis (51\%), tuberculosis (12\%) and salmonellosis ( $8 \%$ ) were the most frequently reported diseases followed by hospitalised cases of varicella ( $7 \%$ ), brucellosis $(6 \%)$ and hepatitis $(6 \%)$. During the study period, clustering of specific diseases like brucellosis, meningitis, mumps, and salmonellosis was observed, indicating possible outbreaks. Our results show that notification system needs to be improved, in order to ensure proper health resources allocation and implementation of focused prevention and control strategies.

\section{Introduction}

The objectives of epidemiological surveillance by mandatory notification of communicable diseases differ depending on the disease, but in general terms they are (i) to describe the ongoing pattern of disease occurrence and to link it to public health action, (ii) to provide information and baseline data for disease investigation and control as well as public health planning and (iii) to study the history and epidemiology of disease [1].

An increasing awareness of challenges posed by the re-emergence of 'old' communicable diseases [2], together with new threats such as Severe Acute
Respiratory Distress Syndrome (SARS), (multidrugresistant tuberculosis (MDR TB), intentional release of biological agents [3] which emerge from increasing globalisation, climate change, international trade and population movements (especially migration and displacement), has stimulated the strengthening of communicable disease-related health resources in the European Union (EU) [4-6]. The first European communicable disease epidemiological report, published in 2007, listed several diseases such as chlamydia infections, campylobacteriosis and gonorrhoea as diseases with the highest incidence in the EU (together with salmonellosis, mumps and tuberculosis) [3]. For chlamydia, campylobacteriosis and gonorrhoea the report stated that trends were rising or stable. Infections with human immunodeficiency virus (HIV) and hepatitis C virus (HCV)-associated infections showed rising trends [3]. To be able to use surveillance data as an element of priority setting for health policies, a well organised notification system is crucial.

In Greece, physicians and laboratories use a standardised notification form to report the mandatorily notifiable diseases if certain criteria are met according to the case definition manual of KEELPNO [7]. At prefectural level, public health departments (PHD) are charged with the collection of data for all notifiable diseases. At national level, KEELPNO receives information from all PHDs for the purpose of carrying out epidemiological surveillance and trend analysis.

Table 1 shows the list of mandatorily notifiable diseases. Overall, they are similar to those in most European countries, with the exception of campylobacteriosis, chlamydia infections, cryptosporidiosis, giardiasis, gonorrhoea, Haemophilus influenzae infections, yersiniosis (non-pestis) and healthcare associated infections for which notification is voluntary. In 2008, syphilis, gonorrhoea, human papilloma virus infections (HPV), herpes simplex virus infections and chlamydia infections were included in the list of mandatorily notifiable diseases in Greece [7]. Over the last two years efforts have been made by the Hellenic Center for Diseases Control (KEELPNO) to reorganise the notification system by redefining the list of 
notifiable diseases and introducing weekly reporting instead of monthly reporting.

International literature has shown that undernotification of communicable diseases, and the resulting underestimation of the disease burden is a major flaw of many surveillance systems, because undernotification limits the efficacy of these systems especially concerning the early identification of possible outbreaks [8-15]. Any surveillance system can only be useful and cost effective if directly linked to the decision-making authorities of the respective country. The linking is needed in order to ensure that public health threats are not only monitored and identified but also contained [1].
The objective of this study was to investigate the completeness of the notification system for communicable diseases in place in western Greece between 1999 and 2004. For the period under study, we also analysed the incidence, seasonality and other characteristics of the communicable diseases in the area.

\section{Methods}

The study was carried out in the prefecture of Achaia in western Greece, which covers an area of 3,271 square kilometres (2.4\% of the total area of Greece). According to the 2001 census, the population of the region was 322,790 ( $3 \%$ of the total population of Greece). For the study period 1999-2004, all official infectious disease

\section{TABLE 1}

Mandatorily notifiable communicable diseases under epidemiological surveillance in Greece, 2010

\begin{tabular}{|c|c|}
\hline Mandatory notification & Diseases under surveillance \\
\hline Immediate & $\begin{array}{l}\text { anthrax; botulism; cholera; diphtheria; encephalitis from arbo-viruses; melioidosis; plague; rabies; } \\
\text { severe acute respiratory syndrome (SARS); tularaemia; smallpox; viral hemorrhagic fevers }\end{array}$ \\
\hline Within 24 hours from diagnosis & $\begin{array}{l}\text { acute hepatitis A; clusters of food- and water- borne infections; enterohaemorrhagic Escherichia coli; } \\
\text { influenza; invasive meningococcal disease; legionellosis; measles; pertussis; meningitis (bacterial, } \\
\text { aseptic); paratyphus; parotitis; rubella; salmonellosis; shigellosis; trichinosis; typhoid fever }\end{array}$ \\
\hline Within a week from diagnosis & $\begin{array}{l}\text { acute hepatitis B, HbsAg(+) in infants; acute hepatitis C, anti-HCV positive (first diagnosis); AIDS/ } \\
\text { HIV; brucellosis; Chlamydia; congenital rubella; congenital syphilis; congenital toxoplasmosis; } \\
\text { echinococcosis; gonorrhoea }{ }^{\text {a }} \text {; herpes simplex virus infections; poliomyelitis; human papilloma } \\
\text { virus infections (HPV) }{ }^{\text {a }} \text { leishmaniasis; leptospirosis; listeriosis; malaria; Q fever; syphilis }{ }^{\text {a }} \text {; tetanus; } \\
\text { tuberculosis; variant Creutzfeldt-Jakob Disease (vCJD); varicella with complications }\end{array}$ \\
\hline
\end{tabular}

a Syphilis, gonorrhoea, human papilloma virus infections (HPV), herpes simplex virus infections and chlamydia infections are included in the list of mandatorily notifiable diseases in Greece only since 2008 , hence outside the period reported in this study.

\section{FIGURE 1}

Monthly distribution of notification rates (median percentage of all notifiable diseases) prefecture of Achaia, western Greece, 1999-2004

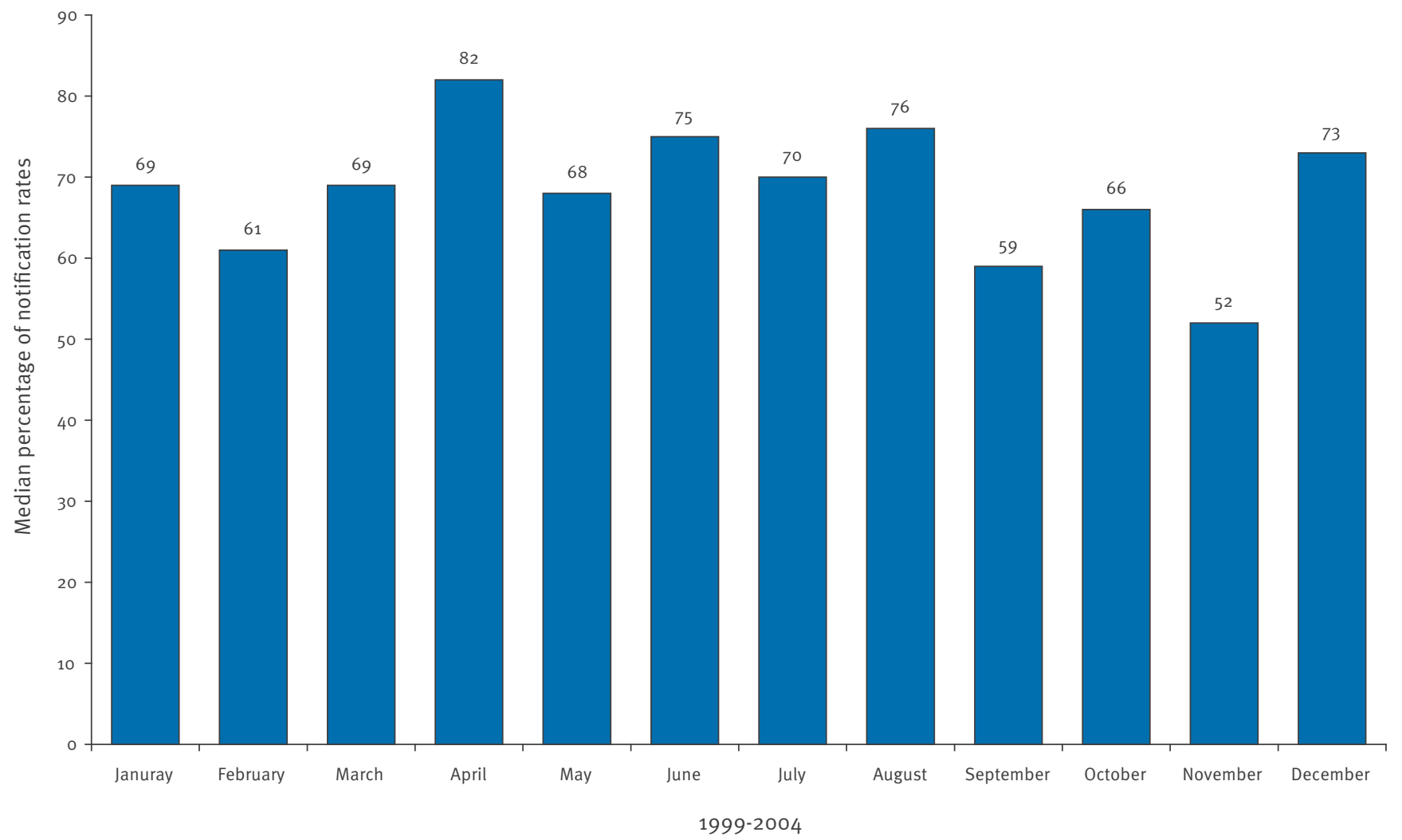


notifications were obtained from the public health department (PHD) of Achaia.

For the same period, all clinical records of cases with mandatorily notifiable infectious diseases were collected by two researchers, trained nurses attending a masters of science course, from three major hospitals in the area covering $70 \%$ of hospital beds in the prefecture of Achaia: the university hospital of Patras (663 beds), the paediatric hospital Karamandaneio, (88 beds) and the general hospital of Aigio (78 beds). Due to access restrictions we did not include the forth hospital in the area ( 355 beds). Non-hospital notification is extremely low and is unlikely to cause a bias in our study.

Researchers traced and confirmed notifiable cases by using three sources. Firstly, the records kept by the hospital-based Committee of Infectious Disease Control which is responsible in each hospital by law for the continuous monitoring of all communicable diseases. Secondly we traced additional cases through the lists of patients who were discharged from the departments of internal medicine, pulmonology and paediatrics of each hospital and at last, by the records kept in handwritten form in a corresponding book logging laboratory results in the departments of microbiology and cytology of each hospital. These laboratory records were also used to confirm all the cases traced. For each case traced that fulfilled criteria for notification, a form was filled by the researchers including data on the date of diagnosis or admission, co-morbidities, criteria used for the ascertainment of the case and demographic characteristics (age, sex, residence and prefecture).

Data collected was then compared with official notification data at the PHD to calculate underreporting. The regional results were also compared to the incidence for the corresponding diseases during the same time period, in Greece, by using data from KEELPNO [16]. Incidence rates (per 100,000 population) were calculated using the 2001 census data provided by the National Statistical Service of Greece.
The study was approved by both the Board of Medical School of the University of Patras and the Regional Health Authority of western Greece. The statistical package for social sciences (SPSS) program-version 16.0 was used for data entry and descriptive analysis.

\section{Results}

During the six-year study period from 1999 to 2004, 966 cases of communicable diseases were reported to the PHD of Achaia; most of the reported cases were in local inhabitants (76\%). Of the 966 reported cases, 707 were notified by the hospitals included in the study, while 259 (27\%) additional cases were notified to the PHD by other sources, mostly by the hospital not included in the study and less than $0.3 \%$ by private practice and health centre physicians.

For the same time period, 1,143 documented cases of communicable diseases that would have fulfilled notification criteria were identified in the three hospitals; most of these cases ( $>90 \%$ ) were traced in the official records of the Committee of Infectious Disease Control. The addition of 259 cases that were notified to the PHD by mainly the fourth hospital sums up to 1,402 cases. After record-linkage and cross-validation of the 1,143 hospital-documented cases, we found that only 707 cases $(62 \%)$ had been reported to the PHD of Achaia, resulting in an observed under notification of $38 \%$ during the six-year study period. In particular, only 368 out of 571 cases identified at the university hospital were notified to the PHD, resulting in a notification rate of $64 \%$. In the Karamandaneio hospital, the notification rate was similar, as 324 of 522 total cases (62\%) were notified to the local PHD. The notification rate decreased to $30 \%$ in the hospital of Aigio, where only 15 of 50 cases were notified. Hence the undernotification rate was $36 \%$ for the university hospital, $38 \%$ for the Karamandaneio hospital and $70 \%$ for the hospital of Aigio. Eighty-eight cases deriving from the hospitals examined and notified to the PHD could not be traced in official hospital archives, indicating incomplete documentation in the archives and unofficial ways of notification.

\section{TABLE 2}

Main characteristics of the nine most frequent communicable diseases notified, prefecture of Achaia, western Greece, 1999-2004

\begin{tabular}{|c|c|c|c|c|c|c|}
\hline & Cases identified & Cases notified & Notification rate in $\%$ & $\begin{array}{l}\text { Annual incidence per } \\
100,000 \text { population }\end{array}$ & $\begin{array}{l}\text { Male/female } \\
\text { ratio }\end{array}$ & $\begin{array}{c}\text { Median age in } \\
\text { years }\end{array}$ \\
\hline $\begin{array}{l}\text { Meningitis } \\
\text { (bacterial and viral) }\end{array}$ & 720 & 550 & 76 & 35 & 1.7 & 9 \\
\hline Tuberculosis & 177 & 92 & 52 & 9 & 2 & 36 \\
\hline Salmonellosis & 105 & 60 & 57 & 5 & 1 & 6 \\
\hline Varicella & 96 & 54 & 56 & 5 & 1 & 7 \\
\hline Hepatitis & 81 & 52 & 64 & 4 & 1 & 12 \\
\hline Leptospirosis & 30 & 17 & 57 & 1 & 6 & 52 \\
\hline Echinococcosis & 26 & 18 & 69 & 1 & 1 & 57 \\
\hline Leishmaniasis & 23 & 17 & 74 & 1 & 1 & 20 \\
\hline
\end{tabular}


Notification rates showed great variation depending on the patients' residence and the season. For local inhabitants rates tended to be rather high, reaching $78 \%$ for the hospitals examined, while notification rates were significantly lower, below $40 \%$, when the patient resided in other prefecture. A higher rate of undernotification was observed in autumn (Figure 1).

Sixty per cent of cases were younger than 15 years with a median of 11 years and $63 \%$ were males. Almost $50 \%$ of the cases were children under the age of 10 , both in the PHD and hospital data.

Meningitis, tuberculosis and salmonellosis were the diseases most frequently notified. The nine most frequently identified diseases represent $96 \%$ of the total cases (Table 2).

Table 2 also shows the notification rate per disease in per cent as well as the annual incidence per disease (observed cases) per 100,000 population in Achaia during the study period and the sex and age distribution.

Diseases with rising trends during the study period were hospitalised cases of varicella and tuberculosis, while diseases with decreasing trends were brucellosis and meningitis. The incidence peaks of brucellosis occurred in 1999, beginning of study period, (37 cases), of meningitis in 2001 (254 cases), of varicella in 2002 (35 cases), of salmonellosis in 2003 (37 cases), of tuberculosis in 2004 (54 cases) and of leptospirosis in 2003 and 2004 (14 cases in two years), indicating possible outbreaks (Figure 2; meningitis data not shown).

A cluster of five mumps cases was observed in the second half of 2002, with only one additional case reported over the study period.

Salmonellosis and leptospirosis showed a greater incidence during the summer, while brucellosis and varicella peaked in the first half of the year (Figure 2). The incidence for meningitis was greater in summer months (higher temperatures) and occurred mainly in urban populations. Only $20 \%$ of cases were identified as having bacterial meningitis. Our data also indicated that viral or aseptic meningitis affects younger people whereas bacterial meningitis affects older patients. Bacterial meningitis was observed more often in winter and viral meningitis more often in summer.

Moreover, our study showed a higher incidence of cases of varicella, salmonellosis, tuberculosis and hepatitis in urban populations than in rural population. In contrast, brucellosis, leptospirosis and leishmaniasis mainly affected rural populations.

There was a clear male preponderance, especially for leptospirosis (6.5:1) and tuberculosis (2.5:1) (Table 2).

\section{FIGURE 2}

Number of cases of specific notifiable diseases during the study period, prefecture of Achaia, western Greece, 1999-2004

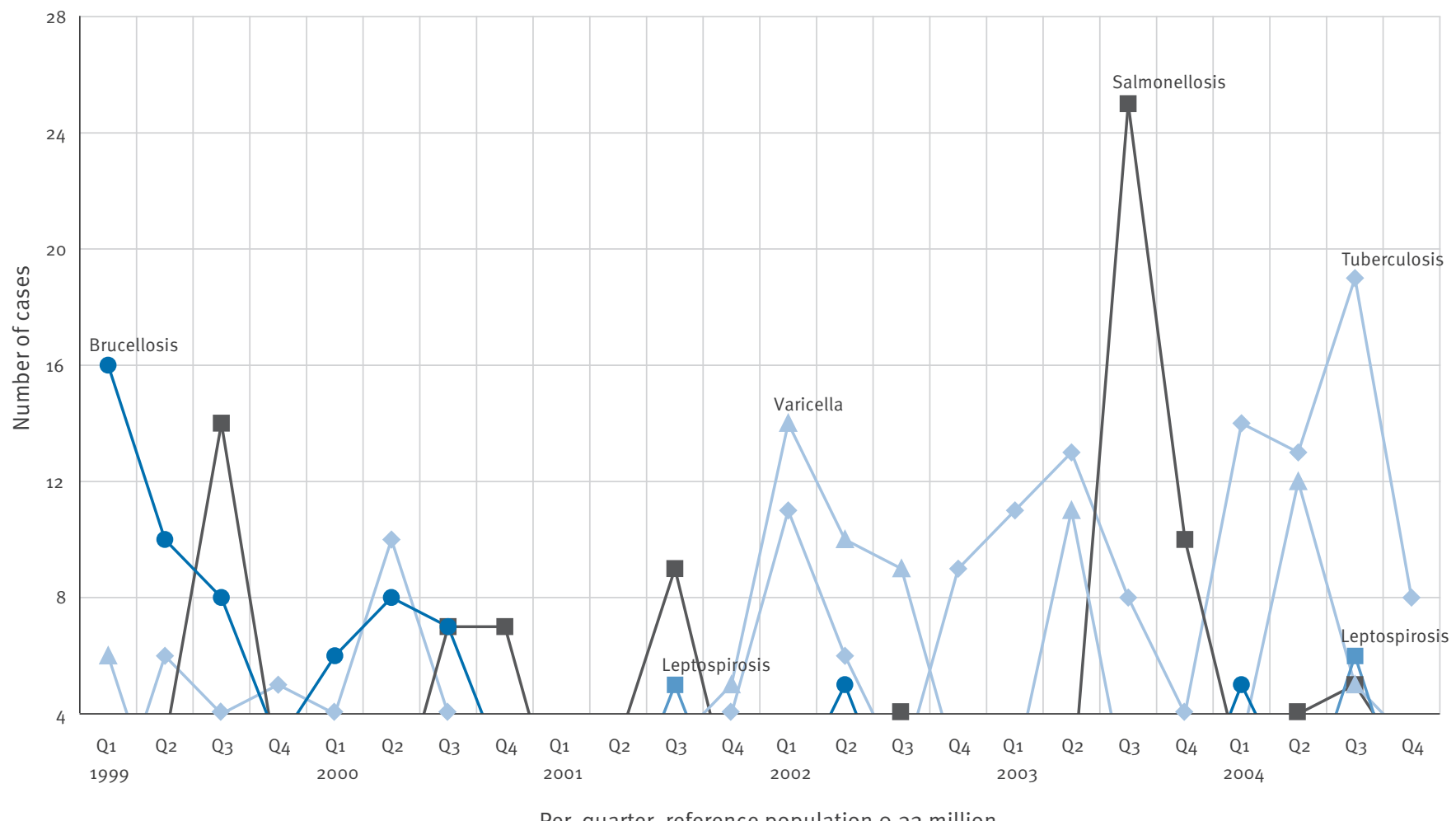

Per quarter, reference population 0,32 million 


\section{Discussion}

The study demonstrates a substantial underestimation of infectious disease incidence and burden in the prefecture of Achaia, western Greece, by present regional surveillance mechanisms, which have not changed significantly during the last years. It is common practice in Greece that cases of infectious diseases are referred from local health centers and private physicians to second and third level hospitals for laboratory verification and treatment. Given the fact that more than one third of the cases (38\%) identified in the hospitals included in the study was not reported to the public health authorities, the corresponding incidence of notifiable infectious diseases for the study period would be at least 1.5 times higher. Several studies have shown that undernotification is observed for most of the notifiable diseases in the majority of Member States in the European Union [8-14] and worldwide [15]. According to our findings, the rate of undernotification was higher for patients from outside the prefecture even though every case should have been notified to the local PHD. Also a higher undernotification in autumn was monitored, which could partly be explained by a reduced alertness of the physicians, because of the decrease in the incidence of infectious diseases following the warmer months.

Obviously the participation of physicians, both in primary and hospital care, in the described mandatory reporting system, may not be so efficient compared with a laboratory reporting system or even a web-based surveillance system that exists in other European countries [17]. Over the last decade several electronic national surveillance systems and specific disease networks have been introduced in several EU countries [18]. The benefits of which in terms of improved timeliness and completeness compared with conventional records have been clearly demonstrated [19]. Several countries, including Greece, may need to look at how best to improve their national standards of electronic disease reporting to be able to compare their data with other EU Member States like the United Kingdom, Germany, the Netherlands and Sweden, where such systems are already in use [19-21]. Low penetration of internet usage in the Greek society, even among health professionals, along with ethical considerations made it difficult to impose a web-based surveillance system in the last decade [22]. However, the latest surveys indicate that internet use is rising in Greece, especially among young, well-educated individuals and health professionals [23]. Under these circumstances, efforts like the Integrated Geographical System for Epidemiological and other Medical Information (GEPIMI) may be effective, for building a web based surveillance system [23].

Among the reasons that may have lead to the noticed undernotification, are the complicated notification forms and the procedures required, as well as the fact that the reporting system was not introduced well to health professionals and other related stakeholders [14]. A pilot sentinel system for improving notifications of private physicians across the country was not successful due to declining participation over the study period [24]. Physicians were discouraged from participating by the number of diseases that they are obliged to report.

At least $50 \%$ of cases in our survey were in children indicating that even though each infectious disease has a specific pattern, children are one of the most affected groups [25-27]. However, an over-representation of children in our data cannot be excluded since one of the three hospitals in the study was a paediatric one. There was also a male preponderance in our data which could partly be attributed to social factors in Greece [28]. Urban/rural distribution is a research field that needs attention in order to understand the epidemiology of any infectious disease, however different social structures across countries could make this element difficult to interpret [29].

A finding worth mentioning is the retrospective identification of possible outbreaks for some diseases in the study period. For example, national data and press confirmed the increase of incidence of viral meningitis in the summer of $2001[16,30]$. However, 2001 was the year when the new combined vaccine for meningitis was introduced in Greece, so this may have played a role in notification of the disease becoming more increased. The notification rate for meningitis was nearly $90 \%$ that year. In 2004, due to the Olympic Games taking place in Greece, the surveillance system was strengthened, by new personnel and informational campaigns on infectious diseases on health services, leading to improved notification rates at least for tuberculosis cases $[16,31]$.

Communicable diseases may spread through uncontrolled immigration of people coming from endemic regions to Greece [32,33]. In 2004, immigrants in Greece numbered more than one million, accounting for $10 \%$ of the population. In the prefecture of Achaia, a continuous influx of of immigrants originating from Asia, namely Pakistan, India, Iraq, and Afghanistan, regions with a high incidence of infectious diseases, was observed in the last decade, however, the majority of immigrants still come from neighbouring countries, especially from Albania (55\%) [30]. Given that cases among immigrants who do not have an official residence are less likely to be notified [33], targeted services that ensure that also these cases are captured should be available.

We acknowledge that the results of this study cannot be extrapolated to the whole national notification system of Greece but are indicative of the magnitude of undernotification that takes place. Variations in notification rates related to residence, to hospital size, to season and to informal reporting need to be studied further to verify the full extent of undernotification and factors influencing it.

To conclude, we believe that reporting of communicable diseases should be improved in regional level. 
The Athens Olympic Games revealed that inadequate training, alertness and limited funding were major drawbacks in system efficacy [31]. Until a more sophisticated system is adopted, simplifying the notification form and KEELPNO providing physicians and PHD personnel with targeted and regular information on trends for specific notifiable diseases and the necessity of completing the notification forms would be measures which could be applied with benefit. In addition, earlywarning systems involving for example primary healthcare services could be utilised.

\section{Acknowledgements}

The authors sincerely thank the nurses loanna Kaltsa and Anna Kalouri for collecting the data for the survey, as well as the Director of Public Health Department of Achaia and the Committees for Infectious Diseases at the University Hospital of Patras, the Paediatric Hospital Karamandaneio and the General Hospital of Aigio for their administrative support and provision of the hospital-based notification data.

\section{References}

1. Declich S, Carter AO. Public health surveillance: historical origins, methods and evaluation. Bull World Health Organ. 1994;72(2):285-304.

2. Vorou RM, Papavassiliou VG, Tsiodras S. Emerging zoonoses and vector-borne infections affecting humans in Europe. Epidemiol Infect. 2007;135(8):1231-47.

3. Guglielmetti P, Coulombier D, Thinus G, Van Loock F, Schreck S. The early warning and response system for communicable diseases in the EU: an overview from 1999 to 2005. Euro Surveill. 2006;11(12). pii=666. Available from: http://www. eurosurveillance.org/ViewArticle. aspx?Articleld=666.

4. Ammon A. [Structure of the Surveillance and management of infectious diseases in the European Union. The EU surveillance networks and the European Centre for Disease Prevention and Control (ECDC)]. Bundesgesundheitsblatt Gesundheitsforschung Gesundheitsschutz 2005;48(9):10381042. [German].

5. Amato-Gauci A, Ammon A. The surveillance of communicable diseases in the European Union - a long-term strategy (2008-2013). Euro Surveill. 2008;13(26). pii=18912. Available from: http://www.eurosurveillance.org/ViewArticle. aspx?Articleld $=18912$

6. Amato-Gauci A, Ammon A. ECDC to launch first report on communicable diseases epidemiology in the European Union. Euro Surveill. 2007;12(23). pii=3213. Available from: http:// www.eurosurveillance.org/ViewArticle.aspx?Articleld $=3213$

7. Hellenic Center for Infectious Diseases Control (KEELPNO). Case definition manual for obligatory notification. Available from: http://www.keelpno.gr/articles/attachments/488 attach1.doc [Greek].

8. Breen E, Ghebrehewet S, Regan M, Thomson AP. How complete and accurate is meningococcal disease notification? Commun Dis Public Health 2004;7(4):334-8.

9. De Greeff SC, Spanjaard L, Dankert J, Hoebe CJ, Nagelkerke $\mathrm{N}$, de Melker HE. Underreporting of meningococcal disease incidence in the Netherlands: results from a capturerecapture analysis based on three registration sources with correction for false positive diagnoses. Eur J Epidemiol. 2006;21(4):315-21.

10. Trottier H, Carabin H, Philippe P. Measles, pertussis, rubella and mumps completeness of reporting. Literature review of estimates for industrialized countries. Rev Epidemiol Sante Publique 2006;54(1):27-39. [French].

11. Lowndes CM, Fenton KA. European Surveillance of STI's Network. Surveillance systems for STIs in the European Union: facing a changing epidemiology. Sex Transm Infect. 2004;80(4):264-71.

12. Gauci C, Gilles H, O’Brien S, Mamo J, Calleja N. General practitioners' role in the notification of communicable diseases - study in Malta. Euro Surveill. 2007;12(11). pii=745. Available from: http://www.eurosurveillance.org/ViewArticle. aspx?Articleld $=745$
13. Krause G, Ropers G, Stark K. Notifiable disease surveillance and practicing physicians. Emerg Infect Dis. 2005;11(3):442-45.

14. Jelastopulu E, Alexopoulos EC, Venieri D, Tsiros G, Komninou G, Constantinidis TC, et al. Substantial underreporting of tuberculosis in West Greece: implications for local and national surveillance. Euro Surveill. 2009;14(11). pii=19152. Available from: http://www.eurosurveillance.org/ViewArticle. aspx?Articleld $=19152$

15. Brissette I, Gelberg KH, Grey AJ. The effect of message type on physician compliance with disease reporting requirements. Public Health Rep. 2006;121(6):703-9.

16. Hellenic Center for Infectious Diseases Control (KEELPNO). National epidemiological data from 1998 to 2008. Available from: http://www.keelpno.gr/keelpno/2008/home/diseases all.pdf [Greek].

17. Rietveld A, Schneeberger PM, Wijkmans CI. [More and faster notification of infectious disease if notification is carried out by the laboratories instead of the diagnosing physician]. Ned Tijdschr Geneeskd. 2005;149(6):304-7. [Dutch].

18. Linge JP, Steinberger R, Weber TP, Yangarber R, van der Goot E, Al Khudhairy DH, et al. Internet surveillance systems for early alerting of health threats. Euro Surveill. 2009;14(13). pii=19162. Available from: http://www.eurosurveillance.org/ ViewArticle.aspx?Articleld $=19162$

19. Ward M, Brandsema P, van Straten E, Bosman A. Electronic reporting improves timeliness and completeness of infectious disease notification, The Netherlands, 2003. Euro Surveill. 2005;10(1). pii=513. Available from: http://www. eurosurveillance.org/ViewArticle.aspx?Articleld $=513$

20. Faensen D, Claus H, Benzler J, Ammon A, Pfoch T, Breuer T, et al.SurvNet@RKI - a multistate electronic reporting system for communicable diseases. Euro Surveill. 2006;11(4). pii=614. Available from: http://www.eurosurveillance.org/ViewArticle. aspx?Articleld $=614$

21. Rolfhamre P, Jansson A, Arneborn M, Ekdahl K. SmiNet-2: Description of an internet based surveillance system for communicable diseases in Sweden. Euro Surveill. 2006;11(5). pii=626. Available from: http://www.eurosurveillance.org/ ViewArticle.aspx?Articleld $=626$

22. Halkias D, Harkiolakis N, Thurman P, Caracatsanis S. Internet use for health-related purposes among Greek consumers. Telemed J E Health 2008;14(3):255-60.

23. Ptochos D, Panopoulos D, Metaxiotis K, Askounis D; Psarras J. Using internet GIS technology for early warning, response and controlling the quality of the public health sector. Int J Electron Healthc. 2004;1(1):78-102.

24. Hellenic Center for Infectious Diseases Control (KEELPNO). Sentinel system using private physicians across the country. Available from: http://www.keelpno.gr/keelpno/2008/home/ EBDO_SENTINEL_2007.pdf [Greek].

25. Wright JA, Polack C. Understanding variation in measlesmumps-rubella immunization coverage--a population-based study. Eur J Public Health. 2006;16(2):137-142.

26. Paul C, van Roode T, Herbison P, Dickson N. Longitudinal study of self-reported sexually transmitted infection incidence by gender and age up to age thirty-two years. Sex Transm Dis. 2009;36(2):63-9.

27. Murray CJL, Lopez AD. Mortality by cause for eight regions of the world: Global Burden of Disease Study. Lancet 1997;349(9061):1269-76.

28. Alexopoulos EC, Geitona M. Self-rated health: inequalities and potential determinants. Int J Environ Res Public Health. 2009;6(9):2456-69.

29. Raza N, Tariq WU, Zaidi SK. Onset of adult varicella in relation to rural or urban origin and its complications. J Coll Physicians Surg Pak. 2008;18(2):95-7.

30. Vravoritou A. Concern about the number of meningitis cases. Eleutherotypia Newspaper 2001; 14 June. [Greek].

31. Panagiotakos DB, Costarelli V, Polychronopoulos E. The perspective of syndromic surveillance systems on public health threats: a paradigm of the Athens 2004 Olympic Games. J R Soc Promot Health. 2007;127(3):111-2.

32. Baldwin-Edwards M. Statistical data on immigrants in Greece: an analytic study of available data and recommendations for conformity with European Union standards. Athens: Mediterranean Migration Observatory, University Research Institute for Urban Environment and Human Resources, Panteion University, 2004:1-80. Available from: http://www. mmo.gr/pdf/general/IMEPO_Final_Report_English.pdf)

33. Linos A, Kotsioni I, Hatziprokopiou P, Riza E. Report on the health of immigrants in Greece. MIGHEALTHNET: Information network on good practice in health care for migrants and minorities.Athens: University of Athens, Medical School, Public Health Department. 2009:16-22. Available from: www. mighealth.net/el [Greek] 